\title{
BOUNDS FOR THE RADII OF UNIVALENCE OF SOME SPECIAL FUNCTIONS
}

\author{
İBRAHIM AKTAŞ, ÁRPÁD BARICZ AND NIHAT YAĞMUR
}

\begin{abstract}
Tight lower and upper bounds for the radii of univalence (and starlikeness) of some normalized Bessel, Struve and Lommel functions of the first kind are obtained via Euler-Rayleigh inequalities. It is shown also that the radius of univalence of the Struve functions is greater than the corresponding radius of univalence of Bessel functions. Moreover, by using the idea of Kreyszig and Todd, and Wilf it is proved that the radii of univalence of some normalized Struve and Lommel functions are exactly the radii of starlikeness of the same functions, and they are actually solutions of some functional equations. The Laguerre-Pólya class of entire functions plays an important role in our study.
\end{abstract}

Mathematics subject classification (2010): 30C45, 30C15, 33C10.

Keywords and phrases: Lommel, Struve and Bessel functions, univalent, starlike functions, radius of univalence and starlikeness, zeros of Lommel, Struve and Bessel functions, Mittag-Leffler expansions, Laguerre-Pólya class of entire functions.

\section{REFERENCES}

[1] Á. BARICZ, Geometric properties of generalized Bessel functions of complex order, Mathematica, 48, 71 (2006), 13-18.

[2] Á. BARICZ, Geometric properties of generalized Bessel functions, Publ. Math. Debrecen 73 (2008), $155-178$.

[3] Á. BARICZ, Generalized Bessel Functions of the First Kind, Lecture Notes in Mathematics, vol. 1994, Springer-Verlag, Berlin, 2010.

[4] Á. BARICZ, D. K. Dimitrov, H. ORHAN, N. YAĞMUR, Radii of starlikeness of some special functions, Proc. Amer. Math. Soc. 144, 8 (2016), 3355-3367.

[5] Á. Baricz, S. Koumandos, Turán type inequalities for some Lommel functions of the first kind, Proc. Edinb. Math. Soc. 59 (2016), 569-579.

[6] Á. BARICZ, P. A. Kupán, R. SzÁsz, The radius of starlikeness of normalized Bessel functions of the first kind, Proc. Amer. Math. Soc. 142, 6 (2014), 2019-2025.

[7] Á. BARICZ, H. ORHAN, R. SZÁsz, The radius of $\alpha$-convexity of normalized Bessel functions of the first kind, Comput. Methods Funct. Theory 16, 1 (2016), 93-103.

[8] Á. Baricz, S. Ponnusamy, Starlikeness and convexity of generalized Bessel functions, Integr. Transforms Spec. Funct. 21 (2010), 641-653.

[9] Á. Baricz, S. Ponnus amy, S. Singh, Turán type inequalities for Struve functions, J. Math. Anal. Appl. 445, 1 (2017), 971-984.

[10] Á. BARICZ, R. SZÁsZ, The radius of convexity of normalized Bessel functions of the first kind, Anal. Appl. 12, 5 (2014), 485-509.

[11] Á. BARICZ, R. SzÁsz, Close-to-convexity of some special functions, Bull. Malay. Math. Sci. Soc. 39, 1 (2016), 427-437.

[12] Á. BARICZ, N. YAĞMUR, Geometric properties of some Lommel and Struve functions, Ramanujan J. 42, 2 (2017), 325-346.

[13] R. K. Brown, Univalence of Bessel functions, Proc. Amer. Math. Soc. 11, 2 (1960), 278-283.

[14] R. K. BRown, Univalent solutions of $W^{\prime \prime}+p W=0$, Canad. J. Math. 14 (1962), 69-78. 
[15] R. K. BRown, Univalence of normalized solutions of $W^{\prime \prime}(z)+p(z) W(z)=0$, Int. J. Math. Math. Sci. 5 (1982), 459-483.

[16] D. K. Dimitrov, Y. B. Cheikh, Laguerre polynomials as Jensen polynomials of Laguerre-Pólya entire functions, J. Comput. Appl. Math. 233 (2009), 703-707.

[17] D. K. Dimitrov, P. K. Rusev, Zeros of entire Fourier transforms, East J. Approx. 17 (2011), 1-110.

[18] T. L. Hayden, E. P. Merkes, Chain sequences and univalence, Illinois J. Math. 8, 3 (1964), $523-$ 528.

[19] M. E. H. Ismail, M. E. MuLdoon, Bounds for the small real and purely imaginary zeros of Bessel and related functions, Methods Appl. Anal. 2, 1 (1995), 1-21.

[20] E. Kreyszig, J. TodD, The radius of univalence of Bessel functions, Illinois J. Math. 4, 1 (1960), $143-149$.

[21] F. W. J. Olver, D. W. Lozier, R. F. Boisvert, C. W. Clark (eds.), NiST Handbook of Mathematical Functions, Cambridge Univ. Press, Cambridge, 2010.

[22] J. STEINIG, The real zeros of Struve's function, SIAM J. Math. Anal. 1, 3 (1970), 365-375.

[23] R. SzÁsz, On starlikeness of Bessel functions of the first kind, In: Proceedings of the 8th Joint Conference on Mathematics and Computer Science, Komárno, Slovakia, 2010, 9 pp.

[24] R. SzÁsz, P. A. KupÁn, About the univalence of the Bessel functions, Stud. Univ. Babeş-Bolyai Math. 54, 1 (2009), 127-132.

[25] H. S. WILF, The radius of univalence of certain entire functions, Illinois J. Math. 6, 2 (1962), 242-244. 